\title{
A Theory of Social Decisions
}

\section{JONATHAN BARON}

\section{A THEORY OF SOCIAL DECISIONS}

Each social institution - from the family to the world - -sets up certain customary ways of making certain kinds of decisions. These methods have advantages and disadvantages, which may be weighed against one another in various ways. The present paper provides a utilitarian analysis of these costs and benefits. It is utilitarian because it assumes that the choice of methods can be made as if the utilities were quantified and compared numerically. Utility is taken to be the extent to which goals are achieved (Baron, 1993). But this particular form of analysis is not central here; any method of comparing costs and benefits will suffice, and probably most methods would yield the same results for the cases considered here.

This analysis is both descriptive and prescriptive. It is a descriptive theory because we might expect people to choose those methods with the highest overall utility. This would be true for two reasons. First, many people probably understand many of the principles to be described here. They are intuitively reasonable. Second, social institutions that, for one reason or another, do not follow these principles are less likely to survive. The theory is prescriptive because it also advises people to follow these principles, both as a way of correcting institutions that do not seem to be functioning well and as a way of setting up new institutions (e.g., writing a constitution). This kind of jointly descriptive and prescriptive theory is in the spirit of "positive" economic theories of law and social custom (e.g., Posner, 1992a,b). The kinds of decisions analyzed here are those made by, or for, families, clubs, departments of organizations, nations, or international institutions.

I shall begin by presenting the theory. Along the way, and at the end, I shall discuss its relation to other empirical and theoretical work.

\section{THE CLASSIFICATION}

The theory relies on a classification of decisions along three dimensions: whether those affected by the decision are the same as those who make it; whether the decision is made by the whole group, a subset of the group, or an individual; 
and whether the decision yields a general rule or a disposition of a particular case. Here is a fuller description of these distinctions:

1. The decision could be made by those who are Affected by it or those who are Unaffected. In the latter case, I assume that the consequences of the decision are imposed on those who are affected with or without their agreement. You might wonder what the "group" is if some of its members are not involved in a decision at all. The answer is that they are subject to the general method of decision making. In general, the members of the group are involved in many different kinds of decisions.

In making this distinction between affected and unaffected, I shall ignore the cases in which the decision is made by both groups, by a subset of those affected, or by those unaffected and a subset of those affected. The conclusions to be drawn about these cases can be, I think, derived straightforwardly from the conclusions I draw about the simpler cases. I shall also ignore unintended effects of decisions (externalities), for these are almost always present, and if I took them into account almost every decision would affect someone other than the decision makers.

2. The decision may be made by the Whole-group, a Subset of the group, or a single Individual. Again, I am assuming a particular group. In many academic departments, decisions about hiring new members are made by the whole group. Other decisions are made by a committee, and still others are made by the chair or a single designated official.

3. The decision may result in a general Rule, to be applied to all cases of a given type until the rule is changed, or a Case-by-case decision. The latter allows what Elster (1985) calls "fine tuning". This is actually a continuum, made even more complex by the fact that single-case decisions set precedents which are seen as binding to varying degrees. A decision about a single case can be seen as the least general rule. Sentencing of criminals is usually case-by-case, although attempts to impose "mandatory sentences" have made it more rule-governed in the U.S. In what follows, for brevity, I use the term "judgment" for a case-bycase decision.

The rules that are used may embody a great variety of principles, and these same principles may be used implicitly in (case-by-case) judgments. For example, all the various principles of equity may be used, alone and in combination. These include equal allocation, allocation according to need, allocation according to contribution, or maximization of some quantity such as utility or wealth (Baron, 1994, ch. 22). ${ }^{1}$ Principles may be simple and crude, or they may attempt to take into account a variety of considerations, such as the rules used to distribute organs for transplanation (Elster, 1993). Principles may also make distinctions among different categories or ranks of individuals, as in Fiske's (1991) mode of "authority ranking" (e.g., distribution of food to men first, then women, then children). Typically, when rules are made by an oligarchy or leader, there is some ranking as well, giving the rule-makers special privileges of some sort. 
These do not necessarily go together, however, and much democratic ideology says that the leader should not get special treatment.

These three distinctions would generate $2 \cdot 2 \cdot 3=12$ cells. When the Wholegroup decides, however, the decision cannot be made by those Unaffected. This eliminates 2 cells, so we are down to the following 10 , which we represent in five pairs - a rule and a judgment in each pair:

1. All for all (affected whole-group). Rules in this category include explicit "social contract" rules such as equality, proportional division of goods, ranking, election of a leader (who then makes decisions using different methods), or agreement to set up a market.

Judgments amount to group decisions about cases. This is a possible way of making decisions, but is not often used. It is inefficient, as the group must spend a great deal of time making decisions. One example is the hiring and promotion of faculty members by an academic department.

2. Some for some (affected subset). Rules of this type include long-term contracts of the sort made in free markets, or treaties made by groups of nations. In the typical case, the decision makers agree unanimously. Anyone who disagrees with the decision can simply withdraw from the subgroup who makes it. When this consists of two people, that amounts to a breakdown of negotiations.

Judgments of this type are one-shot contracts of the sort made in free markets. Likewise, the typical case is unanimous agreement, since anyone who disagrees can withdraw.

3. One for one (affected individual). This includes personal rules that people make for themselves, such as those discussed by Ainslie (1975, 1986, 1991), e.g., a rule to brush one's teeth after every meal.

Judgments of this type are simply personal choices. Each decision is personal, not made for someone else, but these personal decisions may take into account the goals of others.

4. Some for others (unaffected subset). Here, an oligarchy or legislature makes rules. (These rules usually affect the legislators too, but $I$ have included this in the same category.)

The oligarchy or legislature makes case-by-case decisions about others. This is also rare, because many decision-makers are involved, and they do not have the time. One example is the higher courts of the Judiciary system in the U.S., but these courts are seen as setting important precedents, so they are really closer to rule makers than case deciders. Another example is when an entire academic department decides whether to drop a graduate student from its graduate program.

5. One for others (unaffected individual). A single leader can make rules. This is also relatively rare, since the leader, after making the rules, has little to do.

Judgments made by a single leader are more common. This is what judges do, or bureaucrats. Often the judge operates within the context of a rule that specifies how the judgment is to be made. 


\section{AN EXAMPLE}

Consider the problem of a college fraternity. I have in mind a group living arrangement for male college students, in which they share expenses, cooking, housework, and social life. Fraternities see themselves as brotherhoods, often with long traditions. In practice, cooperation often breaks down, despite elaborate initiation rituals designed to insure loyalty. The group must decide on the way in which beer (or milk, or ... .) should be bought and consumed.

The simplest method is One-for-one Judgment, in which each brother buys his own. (Of course, this is a market transaction in the larger society, but we are looking at the fraternity as a group.) If the brothers are altruistic, they will buy beer and put it in the communal refrigerator for all to consume. Consumption is also moderated voluntarily: those who consume a lot will feel obliged either to contribute a lot or to contribute in some other way. This is still One-for-one Judgment, but, with the addition of altruism.

Some-for-some Judgment would correspond to market transactions between pairs of brothers, one buying beer from the other. Some-for-some Rule would involve longer term contracts of this sort - the simplest being a promise to pay back the beer that one has borrowed.

All-for-all Judgment would amount to the whole fraternity deciding on each purchase and each act of consumption, a ridiculous arrangement. All-for-all Rule could specify a particular scheme for payment and consumption. For example, all could be taxed equally, and consumption could be limited to so many bottles per brother per week. This method (All-for-all Rule) could also be used to specify the use of other methods in Judgment decisions: the whole group could specify that all decisions would be Some-for-some Judgment market transactions, for example. These same decisions could be arrived at by any other method of government: One-for-others Rule (a leader) or Some-for-others Rule (a council of leaders).

Leaders could also make Judgment decisions. A beer czar might make individual decisions about payments and consumption (One-for-others Judgment), taking into account ability to pay, rate of consumption, other services to the fraternity, etc. The same could be done by a governing council, although this would be inefficient.

\section{RIGHTS AND DUTIES}

When methods of decision making are well entrenched, they generate rights and obligations. For example, in All-for-all decisions, group members acquire a right to participate in the decision. Citizens of democracies tend to think of this right as natural or categorical rather than contingent. Although it is a right that 
must be respected for the system to function, it is rather a result of the prior choice of a certain method of decision making.

Authority systems (One-for-others and Some-for-others) generate duties of obedience to the authority. On the leader's side, these methods generate obligations of responsibility. Authorities are responsible for the welfare of those in their care. They are often held to a standard that amounts to strict liability: they are blamed for bad outcomes regardless of how they made their decisions.

Market systems (Some-for-some) generate rights to make agreements and duties to honor them. In sum, the various forms of organization generate contingent rights and duties. The utilitarian justification of these rights and duties depends on the utility of the modes themselves as a means to handle different sorts of problems.

\section{ADVANTAGES AND DISADVANTAGES}

The decision-making method that is best suited to a particular problem is determined by several factors: the usefulness in bringing about cooperation or coordination; equity; incentive; speed; effort; participation; sensitivity to the differences among cases; susceptibility to error and abuse; and the costs of education and enforcement. Each of these can be considered as a goal or value in the decision about which decision method is best for a given type of case. Types of cases will differ in the goals that are important and in the extent to which a given method achieves a given goal, so that the best method of decision making will depend on the type of case. This list of goals can be used to devise a fundamental-objectives hierarchy of the sort required by Keeney (1993).

\section{Cooperation and Coordination}

One of the functions of group decisions is to solve social dilemmas by making group members cooperate. The most basic social dilemmas involve the production and consumption of goods. In a "state of nature," it is to the advantage of each person to consume as much as possible and produce as little as possible. One solution to this problem is the idea of money, which can be used as an incentive for production and as a way of moderating consumption. When money is used, the laws connected with its use must be enforced, and this creates second-order social dilemmas in which cooperation is paying the police, reporting thefts, or taking the trouble to vote for anti-crime measures. Many social dilemmas remain unsolved in the modern world, such as overfishing, overpopulation, environmental destruction, and armed conflict. Overpopulation, for example, results from the individual desire of families for more children, which hurts those living in certain 
regions (and, ultimately, everyone). Overfishing has been partially solved by treaties and agreements to limit it.

Problems of coordination are of a different sort. Here, it does not matter much which of several possible rules is followed so long as some rule is followed. Some coordination problems involve setting basic rules for everyone, such as which side of the road to drive on. Other problems involve making distinctions. A traffic light coordinates the flow of traffic through an intersection because it makes a distinction between those allowed to go and those who must stop. Once a solution to a coordination problem is announced, it is generally self-maintaining. It is in everyone's interest to follow the rule. In social dilemmas, on the other hand, people are always tempted to defect, so some enforcement mechanism is required. (Ullman-Margalit, 1977, discusses the role of this distinction in the origin of social norms.)

Social dilemmas can be solved by decisions that affect the whole group (i.e., for-all and for-others, when the "others" include everyone). In the fraternity example, the dilemma could be solved by a rule about purchasing and consumption, and the rule could be made either by the whole group or by the government, which could be one person or a council. When Judgment is used, the decision maker(s) must take into account their more general purpose of encouraging cooperation. A possible example of this is the decision making about allocation of funds by the dean of a college, which is almost always Judgment but which must moderate the demands of different departments with the good of the whole group in mind.

Social dilemmas can also be solved if individuals are sufficiently altruistic (i.e., if they have goals that are dependent on the goals of others in the group). Onefor-one decisions are therefore used in situations that would ordinarily create social dilemmas, but the dilemmas have been solved by inculcation of altruism. In the fraternity example, no "for-all" decisions (those involving power) would be needed, because people would contribute voluntarily to the common beer pool and they would moderate their consumption, taking into account the needs of others. (This method rarely works in fraternities for this purpose, but it does work in other situations, such as roommates, lovers, or spouses.)

Cooperation cannot be brought about by Some-for-some decisions, the basic methods of the market. This is why the "free market" cannot solve problems of overpopulation, environmental destruction, etc., on its own. It might be argued that the market does solve the social dilemma resulting from the tendency to overconsume, but it is not the market itself that solves this problem but rather the institution of property (including money). The institution of property insures that people are not allowed to take whatever they want without following some procedure. This need not be a market procedure. The state could, for example, own everything and dole it out equally. Laws would be needed to prevent theft of state property. Similarly, the market is obviously not the only way to prevent underproduction (although it may be the most effective way). The point here is 
that the institution of property requires a decision affecting the whole group, not a Some-for-some decision.

Coordination differs from cooperation in that it involves no conflict between self and others, so that for-all or for-others decisions are not required to bring it about. Coordination is self-reinforcing, so it can be brought about by Onefor-one decisions if these decisions take into account the precedents set by others. This is presumably how such institutions as languages and customs develop, in part. Coordination problems can also be easily solved by for-all or for-others Rule decisions. Once a rule is stated, everyone has reason to follow it.

\section{Equality and Incentive}

A well-known tension results from the conflict between two arguments. On the one hand, marginal utility is declining for most goods and disutility is increasing for most work. (That is, the utility functions is concave.) Other things being equal, then, the best distribution of both work and goods is equality. One method to achieve equality is to allocate goods or burdens equally in each case. Another method is to allocate goods and burdens according to need or ability to pay, so as to move toward equality by compensating for existing inequality.

On the other hand, any sort of incentive system requires inequality. Goods, such as money, are used to reward work. If everyone were given the same amount of money, this would be impossible (unless everyone happened to work exactly the same amount).

Of course, incentive and equity can be balanced against each other through the calculation of total utility. Certain heuristic rules have developed for division of goods as a function of labor, and these rules can be justified-if at all-as approximations to the normative result that would be obtained by balancing equity and incentive (Baron, 1994, ch. 21). Some rules make the goods received directly proportionate to input (measured in units produced or time worked); these rules essentially ignore equity considerations, although they could achieve reasonable equity in practice. In other cases, some combination of equity and incentive are built into the rule, as when salespeople are paid a fixed salary plus a commission on what they sell.

People often believe that these rules are inherent rights, not subject to deeper justification. The large literature on perceptions of fairness, equity, and justice (see Mellers \& Baron, in press; Baron, 1994, ch. 21) attests to such beliefs.

Different methods of decision making affect equality and incentive differently. Rule-dictating methods (All-for-all Rule and Unaffected Rule) can serve equality and incentive functions well or badly depending on the type of rule that is selected. Obviously, a rule of equal division serves equity well but incentive poorly. A rule in which the amount of goods provided depends directly on the amount of work done serves incentive well but (most likely) serves equity poorly. 
A rule that sets up other mechanisms for decision making can again have a variety of effects. If the rule sets up a market, incentive will typically be well served by the subsequent decisions made in the market. If the decision sets up an authority to make for-others Judgment decisions, the authority can concentrate on either factor or both.

Methods that lead to markets (Some-for-some) by themselves also serve incentive but not equity. One-for-one decisions serve neither function unless the individual is altruistic toward those most in need or inclined to reward others who are productive.

Speed, Effort, and Participation

In general, the more decision makers, the slower the decision. All is slower than Some, which is slower than One. In the military, quick decision making is needed, so most of it is One. Democracy would take too long.

Also, Judgment decisions usually involve more effort than Rules, simply because more decisions must be made.

The minimization of time and effort typically conflicts with another principle, the desire of people to participate in decisions that affect them (Tyler \& Dawes, 1993). This argues for langer groups: All-for-all, or Some-for-some. Note that this principle does not bear on the distinction between Judgments and Rules. Thus, All-for-all Rule decisions form a kind of natural optimum with respect to the conflict between effort and participation: they require some effort, but they do not need to be made very often, and everyone can participate.

\section{Sensitivity}

By sensitivity, I mean the extent to which decisions can be adjusted to individual needs. This is essentially what Elster (1985) called fine tuning. Strict equality rules (under All-for-all Rule) are poor at serving this function. These rules give everyone the same thing (e.g., two bottles of beer per day), whether they want it or not, and they require the same work from everyone, regardless of ability or interest.

More generally, Judgment decisions are more sensitive than Rule decisions. This applies even to One-for-one decisions. A blanket rule against having rich desserts, for example, can fail to take into account the rare case in which eating such a dessert is socially required. The relative value of Judgment and Rule decisions for sensitivity is exactly opposite the relative effort they require. The choice of Judgment vs. Rule decisions should therefore depend on the relative importance of sensitivity and effort (and on the number of cases to which a rule will apply). 
Rule decisions need not be entirely insensitive to individual conditions. The U.S. income tax laws, for example, have attempted to incorporate considerable sensitivity to all sorts of needs (at times too many, as in the case of the "Gallo amendment," inserted in the 1986 tax law essentially to benefit a single family). Such elaborate systems of rules are in between Rule and Judgment in that they also take more time than simple rules. They are most useful when rules must be made for large numbers of cases, as the tax laws are.

\section{Error and Abuse}

An advantage of having decisions made by larger groups, despite the extra time, is that larger groups are less prone to error and (self-serving) abuse. This factor therefore trades off with the speed factor in deciding on the appropriate group size, just as sensitivity trades off with effort in determining whether decisions should be Judgment or Rule. The use of large groups to make decisions is the essential idea of democractic government. When the group is too large, a subset of representatives is chosen, which then acts by authority (Some-for-others) but with All-for-all as a backup method for the selection of the subset in question. Avoidance of error is perhaps one reason why people want to participate in decisions that affect them, although perhaps not the only reason.

Although for-others methods have the advantages of speed, sensitivity, the capacity to consider both equity and incentive, and the capacity to solve social dilemmas and set up systems of coordination, these methods are subject to abuse unless some backup is provided.

In other cases, I should add, for-others methods may be used because onefor-one methods have a different kind of potential for error. Thus, we let parents make decisions for their young children because we think that the parents, on the average, will make better decisions.

\section{Costs of Education and Enforcement}

In general, education and enforcement costs trade off within a given method. If people are effectively taught to follow the law or obey the authority, fewer people will disobey, and enforcement costs will be lower.

Enforcement and education costs are low when a method does not require self-sacrifice. This is true for One-for-one decisions and Some-for-some decisions. Within these methods, however, Rule decisions may require more enforcement than Judgment decisions. For One-for-one decisions, people enforce their own personal rules, for example, by punishing themselves for transgressions, as described by Ainslie. For Some-for-others decisions, long-term contracts need 
to be enforced, often by the parties in question, often by some other outside decision maker.

Education creates dispositions, in the form of virtues, that may transfer to some extent from one situation to another. Cultures differ in their reliance on methods of decision making (Fiske, 1991). Considerable savings can be achieved in education costs, then, if a method draws on dispositions that are already used widely in a culture. This principle applies to cultures of organizations as well as ethnic, tribal, or national groups.

\section{VIRTUES AND VICES}

Modes of decision making generate their own virtues and vices, corresponding to the kind of education that is required to make them work. Market methods, especially Some-for-some Rule (but also Judgment) require honesty in the representation of goods and faithfulness in the keeping of promises (when the decision must be carried out over a long time). Societies support these virtues not only by child training in honesty and faithfulness but also by enforcing good faith contracts through its laws. The vices of these methods are, of course, dishonesty and bad faith, in the sense of not keeping one's word.

Reliance on One-for-one methods requires the virtues of altruism if it is to succeed at solving social dilemmas and establishing equity. It also requires the virtue of industry-internalized rather than enforced-if the work is to get done. The vices of these methods are greed and lack of concern for others.

The use of All-for-all methods requires the virtues of citizenship. Members must be well informed and motivated to serve the interests of the group. Contingent cooperativeness is most helpful in the context of these methods (Baron, 1993, ch. 8). This the willingness to initiate and support rules against defection. For example, it is unreasonable to expect each fisherman to reduce his catch in order to allow fisheries to recover, but we ought to expect him to support regulations that would make all fishermen do this. Likewise, Baron (1985, following John Dewey) argued that rational thinking (in the sense of reasonableness) is a virtue that is necessary for group decision making. The vices of these methods are ignorance, irrationality, and uncooperativeness-the tendency to use the decision-making process only to achieve one's own goals. If these vices are present, the method cannot reliably solve social dilemmas.

Use of authority methods, One-for-others and Some-for-others, require benevolence and concern on the part of the authorities, much like the Confucian ideal of the wise leader. The vices of these methods are abuse of power to serve one's own ends. Societies that set up these methods try to avoid such abuses not only through selection of wise leaders but also through removal of the temptation for abuse for self-serving ends: lifetime tenure for judges, great wealth for kings, 
and, in general, special privileges that leaders might take for themselves if they were not given. Unfortunately, these devices do not always work.

To the extent to which virtues and vices transfer across the various groups to which each person belongs, societies should, and probably do, design their institutions to take advantage of this transfer. We should thus expect similar institutions within a society.

\section{CONCLUSION}

This article has presented an outline of a model for social decision making that is both descriptive and prescriptive. Methods of decision making can be classified by three dimensions - who makes the decision, who is affected, and whether the decision is case-by-case or rule. The utility of various methods in this classification depends on dimensions of the situation, such as the importance of cooperation, coordination, equity, incentive, speed, error, education, and enforcement. Our intuitive attachments to the rights, duties, and virtues of the various forms of organization can thus be justified in general, but, like other intuitions, we might be prone to have them when they cannot be justified (Baron, 1994). This error is, in principle, avoidable through understanding the justification of social organization itself.

The model presented here makes empirically testable predictions about which methods of decision making are used for which kinds of decision. Some of this research could be done simply by examining organizational by-laws or constitutions. The model can also be used prescriptively as a framework for reforming institutional rules or even establishing them.

Jonathan Barn

Department of Psychology, University of Pennsylvania, 3815 Walnut Street, Philadelphia, PA 19104-6196, USA or

(e-mail)baron@cattell.psych.upenn.edu.

Acknowledgements This paper is based on chapter 12 of Baron (1993), which, in turn, was based on previous collaborative work with Alan P. Fiske. The departures from that collaborative work are extensive.

\section{NOTES}

1 Equal allocation occurs in Fiske's (199l) Equality Matching mode, and allocation according to contribution appears to be part of his Market Pricing mode, which also includes decisions made by a subset for itself, i.e., simple market transactions. 


\section{REFERENCES}

AINSLIE, G. (1975). Specious reward: A behavioral theory of impulsiveness and impulse control. Psychological Bulletin, 83, 463-496.

AINSLIE, G. (1986). Beyond microeconomics: Conflict among interests in a multiple self as a determinant of value. In J. Elster (Ed.), The multiple self (pp. 133-175). Cambridge University Press.

AINSIJE, G. (1991). Ricoeconomics: Interaction of actors in a multiple self. New York: Cambridge University Press.

BARON, J. (1985). Rationality and intelligence. New York: Cambridge University Press.

BARON, J. (1993). Morality and rational choice. Dordrecht: Kluwer.

BARON, J. (1994). Thinking and deciding (2nd ed.). New York: Cambridge University Press.

EisTER, J. (1985). Weakness of will and the free-rider problem. Economics and Philosophy, 1, 231-265.

EiSTER, J. (1993). Justice and the allocation of scarce resources. In B. A. Mellers and J. Baron (Eds), Psychological perspectives on justice: Theory and applications (pp. 259-278). Cambridge University Press.

Fiske, A. P. (1991). Structures of social life: The four elementary forms of human relations. New York: Free Press.

KEENEY, R. L. (1993). Value-focused thinking: A path to creative decisionmaking. Cambridge, MA: Harvard University Press.

Mellers, B. A. \& Baron, J. (Eds) (1993). Psychological perspectives on justice: Theory and applications. New York: Cambridge University Press.

POSNER, R. A. (1992a). Economic analysis of law (4th ed.). Boston: Little, Brown.

POSNER, R. A. (1992b). Sex and reason. Cambridge, MA: Harvard University Press.

TYLER, T. \& Dawes, R. M. (1993). Fairness in groups: Comparing the self-interest and social identity perspectives. In B. A. Mellers and J. Baron (Eds), Psychological perspectives on justice: Theory and applications (pp. 87-108). Cambridge University Press.

Uluman-Margailt, E. (1977). The emergence of norms. Oxford: Clarendon Press. 